plications and Prevention Advisory committee and the Policy Advisory Board (POSCH).

Elliot has been on the editorial boards of all of the major cardiovascular journals, and from 1978 to 1983 he was the Editor-in-Chief of Circulation. He has also been Co-Editor of Cardiovascular Drugs and Therapy. His research interests have been widespread but with especial emphasis on the pathophysiology of valvular disease and acute myocardial infarction. From this research he has written over 160 articles in the peer-reviewed literature and 34 book chapters, and he has edited 5 cardiology update books from 1981 to 1990.

Dr. Rapaport continues to be an encyclopedic source of knowledge, especially in all areas of coronary artery disease. He is a consummate teacher sought by medical students, housestaff, and fellows, especially when there are patients in whom the diagnosis or management is difficult. His lectures are superbly organized and proceed in logical and lucid fashion from what is to what is being discovered. For these reasons he is invited as a visiting professor and guest lecturer at institutions throughout the world.

Beyond these accomplishments, there are other facets to Elliot Rapaport. In his youth, Elliot was an accomplished violinist, so much so that one day he received a phone call from Leopold Stokowski to audition for him. Answering the phone, Elliot heard the maestro say, "This is Leopold Stokowski calling." Elliot, thinking that someone was playing a joke on him, answered "Yeah, and I'm Yehudi Menuhin," whereupon the maestro hung up. He never received a second phone call and his music career crashed, fortunately for us and all of cardiology.

Clin. Cardiol. 26, 397 (2003)

\title{
Images in Cardiology: A Case of Global T-Wave Inversions and Impaired Left Ventricular Function Following Intense Emotional Distress
}

\author{
AleXANDER S. Ro, M.D., AND JoEl GELlMAN, M.D.
}

Division of Cardiology, Department of Medicine, University of Maryland, Baltimore, Maryland, USA

A previously healthy 54-year-old woman, taking no medications, presented emotionally upset with mild chest discomfort and nausea after learning of her sister's diagnosis with a terminal malignancy. The initial electrogradiogram (ECG) showed normal sinus rhythm, inferior T-wave flattening, and mild T-wave inversions in $\mathrm{V}_{4}-\mathrm{V}_{6}$ (Fig. 1). Cardiac isoenzymes were elevated, $\mathrm{CPK}=218$ and $\mathrm{CK}-\mathrm{MB}=13.3$ (6.9\%), and electrolytes were normal. On Day 2, prior to coronary angiography, the ECG showed normal sinus rhythm, QTc prolongation to $700 \mathrm{~ms}$, and global, deep, symmetric T-wave inversions (Fig. 2). Cardiac catheterization showed no significant coronary artery disease and moderate systolic dysfunction. By Day 6 the QTc was 500 $\mathrm{ms}$. This syndrome of chest pain, impaired left ventricular function, diffuse symmetric T-wave inversions with a prolonged QTc has previously been documented following intense emotional stress and is thought to result from excessive catecholamines. The changes are reversible and the outcome is favorable.

\section{Reference}

Pavin D, Le Breton H, Daubert C: Human stress cardiomyopathy mimicking acute myocardial syndrome. Heart 1997;78:509-511

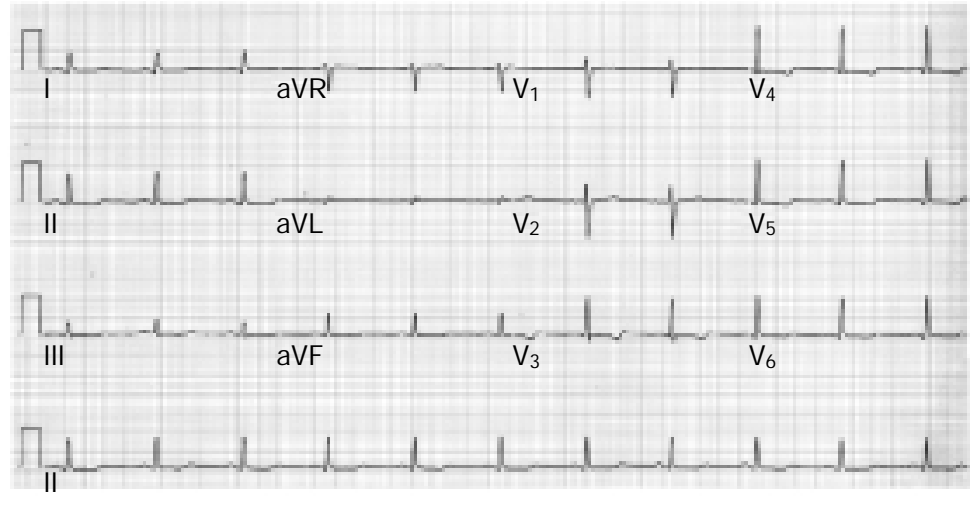

FIG. 1 Initial ECG.

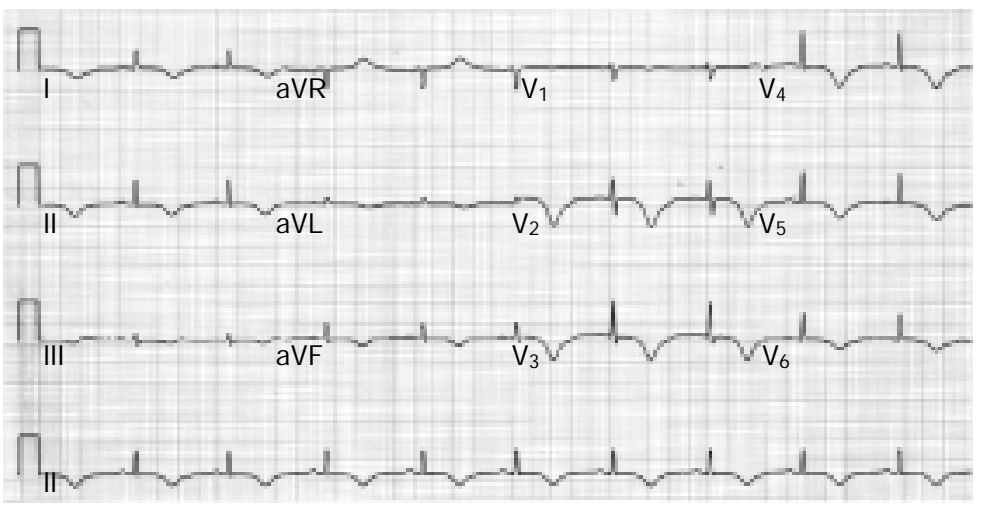

FIG. 2 ECG on Day 2. 